\title{
RET Rearrangement Analysis Was Performed
}

National Cancer Institute

\section{Source}

National Cancer Institute. RET Rearrangement Analysis Was Performed. NCI Thesaurus.

Code C160495.

An indication that RET rearrangement analysis was performed during the study. 